doubling of mean $20^{\text {th }}$-century loss rates (Haeberli et al. 1999, Fig. 3).

Critical points associated with this analysis include: (1) the choice of the starting/end point for the calculation/comparison (the model with the 50-year time interval obviously fits the curve better) and (2) the delay in the onset of terminus reaction to mass balance forcing (a few decades in the case of the Great Aletsch Glacier). The first effect means that an optimal fit has still to be found and the latter phenomenon indicates that today's terminus position of the large glacier reflects climatic conditions around the 1970s or so. In view of the rapid warming during the past two decades, it is highly probable that the glacier tongue would have to be hundreds of meters shorter than now in order to adjust to conditions around the year 2000. The previous minimum extent of Roman times may, therefore, soon be markedly exceeded.

\section{REFERENCES \\ Haeberli, W., Barry, R. and Cihlar, J., 2000: Glacier monitoring within the Global Climate Observing System. Annals of Glaciology, 31, 241 - 246. Haeberli, W., Frauenfelder, R., Hoelzle, M. and Maisch, M., 1999: On rates and acceleration}

trends of global glacier mass changes. Geografiska Annaler, 81A, 585 - 591

Hoelzle, M., Haeberli, W., Dischl., M. and Peschke, W., 2003: Secular glacier mass balances derived from cumulative glacier length changes. Global and Planetary Change $\mathbf{3 6}$ (4), 77 - 89.

Holzhauser, H., 1997: Fluctuations of the Grosser Aletsch Glacier and the Gorner Glacier during the last 3200 years: new results. In: Frenzel, $B$. (Hrsg.): Glacier fluctuations during the Holocene. Paläoklimaforschung/Palaeoclimate Research 24, 35-58. Special Issue: ESF Project European Palaeoclimate and Man 16. Gustav Fischer Verlag Stuttgart, Jena, Lübeck, Ulm

Holzhauser, H. and Zumbühl, H. J., 1999: Glacier fluctuations in the Western Swiss and French Alps in the 16th century. In: Pfister, C. / Brázdil, R. (eds.): Climatic Variability in Sixteenth-Century Europe and Its Social Dimension. Climatic Change 43, 223 $-237$.

\title{
Cyclical Climatic-Environmental Changes in the Mediterranean Area (2500 BP-Present Day)
}

\author{
Franco 0rtolani ${ }^{1}$ and Silvana Pagliuca ${ }^{2}$ \\ 'Dipartimento di Pianificazione e Scienza del Territorio, Università di Napoli Federico II, Napoli, Italy; fortolan@unina.it \\ ${ }^{2} I S A F O M, C N R$, via Cupa Patacca, Ercolano, Napoli, Italy; pagliuca@ispaim.na.cnr.it
}

The Mediterranean area acts as a boundary zone between humid and desert zones and is highly sensitive to variations in climate and environment. Indeed, shifts in the climate bands towards north or south by only a few degrees of latitude may result in dramatic changes in soil surface conditions. This may cause, for example, desertification in areas that previously had a humid climate or vice versa.

Multidisciplinary geoenvironmental research was carried out to shed light on the climatic significance of different sediment types that have accumulated over the last 2500 years (Fig. 1), located at various latitudes and in geographical areas with different morphoclimatic conditions (Ortolani et al., 1991; Ortolani and Pagliuca, 1993, 1994, 2001). The sediments, which cover many archaeological sites, were not affected by human impact between the Archaic Period and the Middle Ages.

In the Mediterranean area, the presence of wind-borne sand in coastal dunes (Als, Fig 1) is the most significant geoenvironmental indicator linked to warm-arid climatic conditions. Under conditions of heightened aridity (rainfall lower than $200 \mathrm{~mm}$, typical of

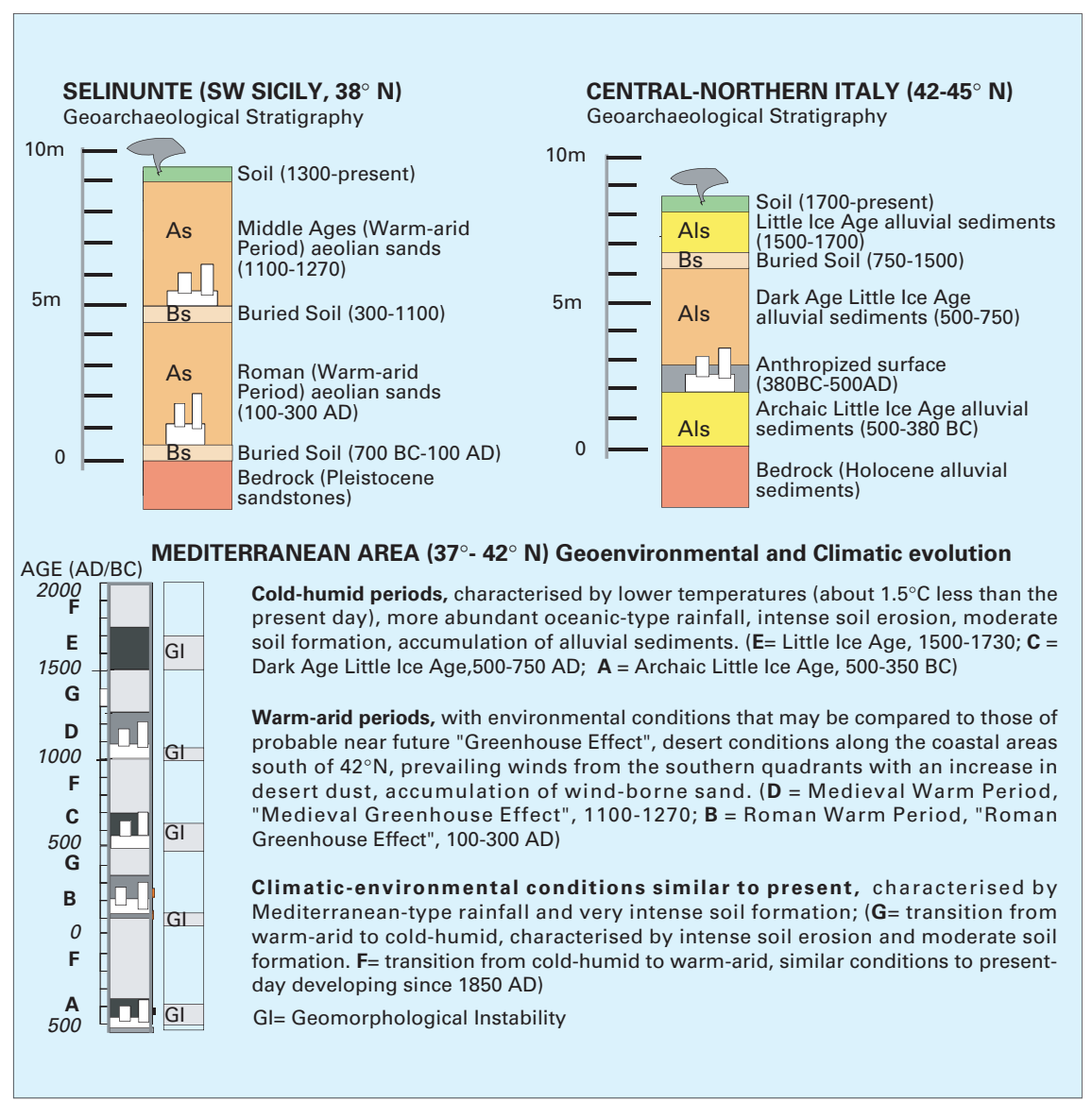

Fig. 1: Mediterranean Area Geoarchaeological Stratigraphy and Geonvironmental-Climatic Evolution (2500 BP-Present Day).

desert areas), wind-borne coastal sand may even invade areas a considerable distance from the sea, forming wind-borne accumulations that cause the vegetation cover to disappear. This has been widely shown in the literature and verified by direct research (Ortolani and Pagliuca, 2001). 


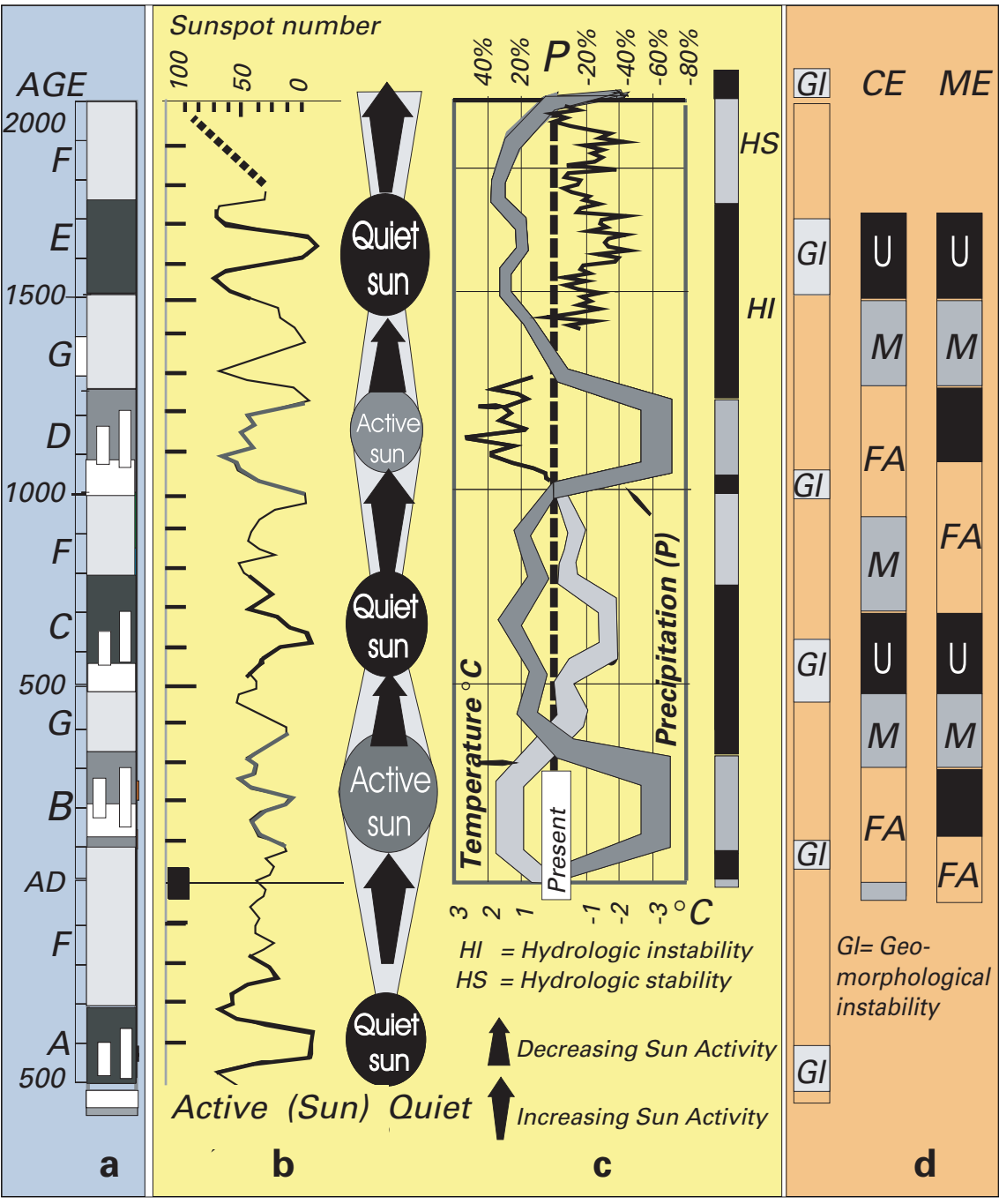

Fig. 2: (a) Correlation between Mediterranean Area Geonvironmental-Climatic Evolution, (b) Solar Activity, (c) Temperature-Precipitation and (d) Socio-Economic Conditions. CE = Central Europe; $M E=$ Mediterranean Area South $42^{\circ} \mathrm{N} ; \mathrm{FA}=$ Favourable; $U=$ Unfavourable; $M=$ Moderately Favourable).

The most typical sediment characterising wetlands consists of soil that allows the development of vegetation and which differs according to latitude, local climatic and morphological conditions, and substrate lithology (Ortolani and Pagliuca, 2001). The vegetation occurs both on the surface of coastal sand dunes, which are thus stabilised, and on the alluvial sediments of the plains and altered substrate of the rocks of hill and mountain slopes.

The most significant sediments found in Mediterranean coastal dune zones in which severe climatic and environmental changes have occurred in the past consist of buried soils within layers of windborne sand (As, Fig 1). The presence of buried soils indicates that precipitation increased appreciably for a sufficiently long period of time to allow soil formation. Hence, there was a change in climatic conditions from desert to humid. Sediments indicating considerable climatic changes in currently humid areas include wind-borne sand (As, Fig. 1) and alluvial deposits of considerable thickness that cover areas where human impact has occurred (Als, Fig. 1). The presence of windborne sand indicates that rainfall decreased sharply until desertification (rainfall below $200 \mathrm{~mm}$ ) resulted (Ortolani and Pagliuca, 2001).

During the peak of warm-arid climatic changes, "greenhouse effect" environmental conditions similar to those expected in the near future were established (Figs. 1 and 2). During the transition periods from humid to warm-arid and at the beginning of cold-humid climatic variations, other significant geoenvironmental variations (hydrologic
(HI) and geomorphological (GI) instability) occurred concurrently with the marked increase in rainfall that took place after warm periods (figures 1 and 2).

During periods in which the temperature increased by $1-2{ }^{\circ} \mathrm{C}$, coastal zones were affected by desertification up to about latitude $42^{\circ} \mathrm{N}$ (Fig. 1). During temperature decreases, the areas of alluvial plains subject to human impact and settlements were affected by an accumulation of huge volumes of sediments. This resulted in aggradation and progradation of the coastlines in the northern part of the Mediterranean, while soil formation occurred on the surface of the coastal dunes in the southern and northern parts (Fig. 1).

The main result achieved through geoarchaeological research is the identification of cyclicity (period of about 1000 years) of the major climate and environmental changes that have resulted in 100- to 200year environmental crises (Fig. 1). Paleoenvironmental, paleoclimatic and geoarchaeological data show that the Mediterranean area was chiefly affected by environmental conditions similar to those of the present day (Figs. 1 and 2) (Ortolani and Pagliuca, 2001).

There is clearly a close correlation between climatic and environmental changes and solar activity. Prolonged solar activity maxima coincide with warm "greenhouse effect" periods and repeated solar activity minima coincide with cold periods, such as the Little Ice Ages (Figs. 1 and 2a, b). The history of mankind and the environment in the last few millennia highlights progressive, cyclical climatic and environmental changes that consistently occur in multicentennial periods (Figs. 1 and 2a).

Using instrumental data and those obtained from natural archives, we propose a climatic reconstruction of the past 2500 years (Fig. 2c). Variations in rainfall are expressed as percentages of current values.

A valid frame of reference for assessing and quantifying the changes that will occur at different 
latitudes during the Greenhouse Effect of the Third Millennium is provided by: (1) climatic and environmental data relating to the Warm Medieval Period in the Mediterranean area; (2) results achieved from research into geoenvironmental changes linked to historical climatic variations, especially those of the last few centuries, and; (3) various multidisciplinary data obtained from research conducted in various parts of the world (Fig. 2).

Instrumental data chiefly concerning the last 150 years in the Mediterranean show a consistently close correlation between environmental variations (increase in solar activity and temperature and changes in the quality and quantity of rainfall) and the period of transition from the cold-humid climatic conditions of the Little Ice Age to those that may probably characterise the Warm Period of the Third Millennium (Greenhouse Effect of the Third Millennium).

If cyclical climatic variation as occurred in the past will continue, it might result in new environmental conditions along the belts bordering the current climatic zones. In particular, a large part of the areas that are currently subtropical deserts might be transformed into humid areas. These conditions may be at times better and at times worse than those of the Little Ice Age.

This speculated shift in Mediterranean climatic conditions a few degrees to the north would cause an appreciable change in rainfall in central-northern Europe. Since the $18^{\text {th }}$ century, this area has been characterised by an almost homogeneous distribution of rainfall over the year and consequently, a constant river water regime. Mediterranean-type rainfall could probably increasingly affect this area in the near future. This seasonalisation of rainfall would result in an increased frequency of bankful flow conditions. Ongoing millennial climatic cyclicity (Fig. 2) forecasts that river valleys will be affected by repeated catastrophic flooding. Given that these valleys were ur- banised on the basis of a constant river water regime, serious damage to the consolidated socio-economic organisation of central-northern Europe would therefore result.

\section{REFERENCES}

Allocca, F., Amato, V., Coppola, D., Giaccio, B., Ortolani F. and Pagliuca, S., 2000: Cyclical ClimaticEnvironmental Variations during the Holocene in Campania and Apulia: Geoarcheological and Paleoethnological Evidence. Mem. Soc. Geol. It., 55, 345-352.

Brazdil, R., Glaser, R., Pfister, C. and Stangl, H., 2002 Floods in Europe. A look into the past. Pages News, 10/3, 21-23

Jirikovic, J. L., and Damon, P. E., 1994: The Medieval solar activity maximum. Climatic Change, 26, 309-316.

Ortolani, F. and Pagliuca, S., 2001: Le variazioni climatiche storiche e la prevedibilità delle modificazioni relative all'effetto serra. Asociazione Italiana Nucleare, marzo 2001, Roma.

Stuiver, M., Braziunas, T. F., Becker, B. and Kromer, B., 1991: Climatic, Solar, Oceanic and Geomagnetic influences on late glacial and Holocene Atmospheric 14C/12C change. Uuaternary Research, 35, 1-24.

\title{
Abrupt Warming of the Intermediate-Depth Atlantic Ocean in Response to Thermohaline Circulation Slowdown During the Last Deglaciation
}

\author{
Carsten Rühlemann, Stefan Mulitza, Gerrit Lohmann, André Paul, Matthias Prange, Gerold Wefer \\ Department of Geosciences and Research Center Ocean Margins, University of Bremen, 28334 Bremen, Germany; ruehl@uni-bremen.de; \\ smul@palmod.uni-bremen.de
}

Climate modeling studies predict that anthropogenic increases in greenhouse-gas concentrations will possibly cause a weakening or even a shut-down of the meridional overturning circulation in the Atlantic (thermohaline circulation, THC), through global warming and an intensification of the hydrological cycle (Cubasch et al., 2001). Therefore it is essential to monitor the Atlantic THC, preferably on a permanent basis. Present field observations of the THC, however, are insufficient to detect whether its strength is changing. Climate models exhibit pronounced and rapid warming of the tropical intermediate-depth Atlantic Ocean in consequence of a THC slowdown, suggesting that mid-depth Atlantic temperatures may serve as an indicator of THC change. Applying different forcings to an ocean general circulation model, representing present-day and glacial climates, we show that this mid-depth water response is a robust feature in both climatic situations (Fig. 1). Given that dramatic changes of the THC occurred during the last deglaciation, the reconstruction of Atlantic intermediate-depth temperatures from sediment cores provides an opportunity to evaluate the reliability of the model simulations and the suitability of tropical mid-depth Atlantic temperature change as a tracer of THC strength. For this purpose we studied two sediment cores recovered from high accumulation areas, southeast of the island of Grenada (M35003-4; 1205' N, 61ำ' W; 1299 $\mathrm{m}$ water depth) and off the coast of
Angola (ODP 1078C; $11^{\circ} 55^{\prime} \mathrm{S}, 13^{\circ} 24^{\prime}$ E; $426 \mathrm{~m}$ water depth). Site M35003 is located in the transition zone between Antarctic Intermediate Water and Upper North Atlantic Deep Water while ODP Site $1078 \mathrm{C}$ is situated within the South Atlantic Central Water. In order to reconstruct intermediate-depth temperatures for the last deglaciation we measured the oxygen isotope composition of the endobenthic foraminifer Bolivina dilatata along ODP core $1078 \mathrm{C}$ with an average temporal resolution of 65 years for the time interval 24,000 to 8,000 calendar years before present (24 - 8 cal. kyr BP). The $\delta^{18} \mathrm{O}$ record of the benthic foraminifera Cibicidoides wuellerstorfi for the Caribbean core M35003-4 (Hüls, 2000 ) has an average resolution of 330 years. 